\title{
The impact of ischemia-reperfusion injury on the effectiveness of primary angioplasty in ST-segment elevation myocardial infarction
}

\author{
Aleksander Araszkiewicz, Marek Grygier, Maciej Lesiak, Stefan Grajek \\ $1^{\text {st }}$ Department of Cardiology, Poznan University of Medical Sciences, Poland
}

Postep Kardiol Inter 2013; 9 , 3 (33): 275-281

DOI: 10.5114/pwki.2013.37509

\begin{abstract}
The most effective method of reperfusion in patients with ST-segment elevation myocardial infarction (STEMI) is primary percutaneous coronary intervention ( $\mathrm{PCl}$ ), assisted by aspiration thrombectomy and administration of antiplatelet agents and anticoagulants. However, effective restoration of blood flow in the infarct-related artery may paradoxically result in further damage to the heart muscle. This phenomenon, called ischemia-reperfusion injury (IRI), can significantly reduce the beneficial effects of reperfusion therapy. The rapid restoration of blood flow to the previously ischemic area causes a number of pathophysiological mechanisms leading to increased necrosis of myocytes still viable at the end of the ischemic period. It has been postulated that there are several strategies that can reduce damage to the heart muscle. Attempts to translate the results of experimental trials has been disappointing. More recently, however, some of the clinical benefits of ischemic postconditioning in which reperfusion in patients with STEMI who are undergoing $\mathrm{PCl}$ is interrupted with short episodes of ischemia were demonstrated. This renewed the interest in the reperfusion phase as a target for cardioprotective therapy. Research in this field has also been reinforced by the discovery of new potential targets for treatment that protects against IRI, such as the kinase pathway to protect against damage (reperfusion injury salvage kinases - RISK) and mitochondrial permeability transition pore. It seems that these findings will help to develop strategies that will improve the efficiency of mechanical reperfusion and may translate into long-term clinical effects.
\end{abstract}

Key words: reperfusion, myocardial infarction.

\section{Introduction}

Effective reperfusion of the occluded coronary artery led to a reduction of myocardial necrosis and significantly improved the prognosis in acute ST-segment elevation myocardial infarction (STEMI) [1]. For the past two decades mortality in STEMI decreased from more than $15 \%$ to less than $5 \%$ [2]. Such a significant reduction is mainly due to improvements in the availability and efficacy of reperfusion therapy, in particular primary percutaneous coronary intervention $(\mathrm{PCl})$. Currently, in addition to primary angioplasty with stent implantation, manual aspiration thrombectomy and modern, fast-acting antiplatelet agents and anticoagulants have been widely introduced into clinical practice, which further improved the efficiency of reperfusion.

However paradoxically, effective reperfusion therapy and restoration of blood flow in the infarct-related artery may, in some cases, lead to further damage to the heart muscle. This phenomenon is called ischemia-reperfusion injury
(IRI) and it can significantly reduce the beneficial effects of reperfusion.

The rapid blood flow to the previously ischemic area causes a number of pathophysiological mechanisms leading to increased necrosis of myocytes which were still viable at the end of the ischemic period and to extension of the infarct zone [3-5]. It is estimated that IRI is responsible for approximately $50 \%$ of the final infarct area [6]. Therefore, almost 30 years ago Braunwald called reperfusion a "double-edged sword" [7].

Exploration how to reduce IRI in clinical practice, and thus further how to reduce myocardial necrosis, is particularly important in the era of rapid development of interventional cardiology. It is known that the area of necrosis, and in consequence the area and the extent of left ventricular remodeling, are the factors determining the patient's prognosis [8].

The presence and severity of IRI has been the subject of debate. The uncertainty was caused by the inability to

Corresponding author:

Aleksander Araszkiewicz MD, 1 ${ }^{\text {st }}$ Department of Cardiology, Poznan University of Medical Sciences, 1/2 Długa St, 61-848 Poznan, Poland, tel.: +48 6185492 93, 608574 375, fax: +48 618549 094, e-mail: aaraszkiewicz@interia.pl

Received: 5.02.2013, accepted: 16.08.2013. 
accurately assess the progression of necrosis in vivo in the transition from ischemia to reperfusion [9]. The most convincing way to prove the existence of reperfusion injury is to demonstrate that it is possible to reduce the size of myocardial infarction by interventions applied at the beginning of myocardial reperfusion [3].

In animal and experimental models a number of strategies have been shown to ameliorate lethal reperfusion injury. The translation of these beneficial effects into the clinical setting has been disappointing. Nevertheless, recent demonstrations of the benefit of ischemic postconditioning, in which myocardial reperfusion in patients with acute myocardial infarction who are undergoing PCI is interrupted with short-lived episodes of ischemia, have regenerated interest in the reperfusion phase as a target for cardioprotection. The identification of the reperfusion injury salvage kinase (RISK) pathway and the mitochondrial permeability transition pore (MPTP) as new targets for cardioprotection has also intensified research in this area. It seems that these findings will help to develop strategies that will improve the efficiency of mechanical reperfusion and possibly translate into long-term clinical effects.

\section{How is reperfusion injury manifested clinically?}

It has been proven that clinically IRI is the reason for the four major types of cardiac dysfunction. The first type is myocardium stunning - mechanical dysfunction persisting after reperfusion despite the absence of irreversible myocyte damage and despite the restoration of normal coronary flow [10]. Improvement appears usually within a few days or weeks after myocardial infarction. Secondly, IRI leads to the "no-reflow" phenomenon. It is the inability to reperfuse the ischemic area due to changes in coronary microvasculature (endothelial cell swelling, microthrombosis, inflammatory infiltrations) [11, 12]. In coronary angiography, "no-reflow" can be seen as a flow in the infarct-related artery $<$ TIMI 3, despite effective and complete recanalization and/or lack of tarnishing of the myocardium ("blush") as an expression of reperfusion at the level of the coronary microcirculation (myocardial blush grade or TIMI myocardial perfusion grade <2) - Table 1. Electrocardiographically the sign of the "no-reflow" phenomenon is the lack of full normalization of the ST segment elevations after successful PCI.

Table 1. Angiographic markers of reperfusion in the infarct-related artery and in the coronary microcirculation

\begin{tabular}{|c|c|}
\hline \multicolumn{2}{|c|}{ TIMI grade coronary flow } \\
\hline TIMI 3 & Normal coronary flow \\
\hline TIMI 2 & $\begin{array}{l}\text { Dye passes the whole artery but significantly slower in the distal part of the vessel than in contra- or ipsilateral } \\
\text { artery ( }>3 \text { cardiac cycles) }\end{array}$ \\
\hline TIMI 1 & $\begin{array}{l}\text { The contrast material passes beyond the area of obstruction, but "hangs up" and fails to opacify the entire coronary artery } \\
\text { distal to the obstruction for the duration of the cine run }\end{array}$ \\
\hline TIMI 0 & No antegrade flow beyond the point of occlusion \\
\hline \multicolumn{2}{|r|}{ Myocardial Bush Grade (MBG) - is based mainly on the INTENSITY of the opacification of the myocardiumin the distribution of the culprit lesion } \\
\hline MBG 3 & $\begin{array}{l}\text { There is well visible ground glass appearance ("blush") or opacification of the myocardium in the distribution of the culprit } \\
\text { artery similarly to the area of distribution of contra- or ipsilateral artery }\end{array}$ \\
\hline MBG 2 & $\begin{array}{l}\text { There is visible blush in the distribution of the culprit artery but worse than in the area of distribution of contra- } \\
\text { or ipsilateral artery }\end{array}$ \\
\hline MBG 1 & Minimal blush in the distribution area of the culprit artery \\
\hline MBG 0 & $\begin{array}{l}\text { There is no blush in the distribution of the culprit artery or persisted blush (dye staining is present on the next injection) } \\
\text { - lack of tissue level perfusion }\end{array}$ \\
\hline \multicolumn{2}{|r|}{$\begin{array}{l}\text { TIMI Myocardial Perfusion Grade (TMPG) - is based mainly on the DURATION of opacification of the myocardiumin the distribution } \\
\text { of the culprit lesion }\end{array}$} \\
\hline TMPG 3 & $\begin{array}{l}\text { Normal entry and exit of dye from the microvasculature. There is the ground glass appearance ("blush") or opacification } \\
\text { of the myocardium in the distribution of the culprit lesion that clears normally, and is either gone or only mildly/moderately } \\
\text { persistent at the end of the washout phase (i.e. dye is gone or is mildly/moderately persistent after } 3 \text { cardiac cycles } \\
\text { of the washout phase and noticeably diminishes in intensity during the washout phase) }\end{array}$ \\
\hline TMPG 2 & $\begin{array}{l}\text { Delayed entry and exit of dye from the microvasculature. There is opacification of the myocardium that is strongly } \\
\text { persistent at the end of the washout phase i.e. dye is strongly persistent after } 3 \text { cardiac cycles but less than } 30 \mathrm{~s}\end{array}$ \\
\hline TMPG 1 & $\begin{array}{l}\text { Dye slowly enters but fails to exit the microvasculature. There is opacification of the myocardium that fails to clear from } \\
\text { the microvasculature, and dye staining is present on the next injection ( }>30 \mathrm{~s} \text { between injections) }\end{array}$ \\
\hline TMPG 0 & Dye fails to enter the microvasculature. There is no blush in the distribution of the culprit artery - lack of tissue level perfusion \\
\hline
\end{tabular}


Thirdly, IRI might be the cause of reperfusion associated arrhythmias [13]. And the fourth type of reperfusion injury is myocardial necrosis and apoptosis with greater than expected systolic dysfunction and left ventricular remodeling [3]

\section{Mechanisms of ischemia-reperfusion injury}

For the first time reperfusion injury in the heart was demonstrated by Jennings et al. [14]. They described the histological features of reperfused ischemic canine myocardium in which cell swelling, contracture of myofibrils, disruption of the sarcolemma and the appearance of calcium phosphate microparticles in the mitochondria were observed.

As a result of coronary artery occlusion, a significant number of pathophysiological mechanisms associated with reduced cardiac access to oxygen and glucose occur. The amount of intracellular ATP decreases, functions of ion pumps and enzymes are impaired and the permeability of cell membranes and intracellular calcium concentration increases rapidly [15-17]. In the extracellular space and intracellularly $\mathrm{pH}$ drops as a result of accumulation of $\mathrm{H}^{+}$ions (mainly due to the accumulation of excess lactic acid), and osmolality increases due to intracellular accumulation of osmotically active substances [15-17]. Infarct-related artery recanalization and rapid reflow of oxygenated blood to the ischemic area cause a sudden change in the extracellular environment and adverse metabolic changes. Reperfusion leads to rapid correction of $\mathrm{pH}$ due to lactic acid leaching and activation of the $\mathrm{Na}^{+} / \mathrm{H}^{+}$exchanger ( $\mathrm{pH}$ paradox). This leads to an increase in sodium ion concentration in the cell, then to inhibition of retrograde $\mathrm{Ca}^{2+}$ transportation through the $\mathrm{Na} / \mathrm{Ca}$ exchanger, or even its reversal, which increases intracellular $\mathrm{Ca}^{2+}$ accumulation. Consequently, the activation of a number of enzymes and contractile apparatus leads to contraction of the cardiomyocyte in the early stage of reperfusion [3-5]. Sudden reperfusion also induces oxidative stress due to the influx of oxygenated blood and inflammatory cell activation (oxygen paradox) [18]. Reactive oxygen species (ROS) (free radicals) cause lipid peroxidation of the cell membrane and damage to various intracellular enzymes, and DNA $[18,19]$. Moreover, the permeability to $\mathrm{Ca}^{2+}$ ions and cell calcium overload increases. An important component of the IRI is also infiltration of inflammatory cells and endothelial cell swelling, rapid deterioration of endothelial function and microthrombosis, which lead to the "no-reflow" phenomenon $[12,18]$. These mechanisms (calcium ion overload, increased ROS, pH correction) lead to prolonged opening of a non-selective channel in the inner mitochondrial membrane - mPTP [20, 21]. Mitochondrial permeability transition pore plays a central and crucial role in the phenomenon of reperfusion injury. The opening of the channel causes deep and usually irreversible changes in mitochondrial bioenergetics and leads to the start of mechanisms causing necrosis and apoptosis of cardiomyocytes. The rapid increase of mitochondrial membrane per- meability to ions and molecules (> $1.5 \mathrm{kDa}$ ) leads to swelling of the matrix, the disappearance of membrane electrochemical gradient and inner mitochondrial membrane rupture. This leads to phosphorylation uncoupling, the loss of ATP and $\mathrm{NAD}^{+}, \mathrm{Ca}^{2+}$ ion leakage and, consequently, the disintegration of the mitochondrion. As a result of reduction of the redox potential there occurs additional production of reactive oxygen species (RIRR - ROS-induced ROS release) and leakage of pro-apoptotic enzymes such as cytochrome C [19-22]. These mechanisms lead to rapid necrosis of many hitherto live myocytes and sudden cardiac infarct zone expansion with all clinical consequences. The prevention of mPTP opening seems to be the key mechanism for all cytoprotective strategies against IRI.

\section{Modification of reperfusion (postconditioning)}

In 2003, Zhao et al. documented in a canine model the effectiveness of intermittent episodes of ischemia and reperfusion applied after prolonged closure of the infarct-related artery [23]. The left anterior descending artery in dogs was ligated for 45 min and then there were performed intermittent periods of reperfusion and re-occlusion ( $3 \times 30 \mathrm{~s})$. The authors observed $44 \%$ reduction in infarct size as compared with the control group. For such a procedure the term postconditioning (POSTCON) was adopted. A few postulated mechanisms of cytoprotective effects of POSTCON exist. It has been shown that modification of reperfusion affects important mediators of lethal reperfusion injury, reducing oxidative stress, rapid washout of adenosine, osmotic shock and intracellular calcium ion overload. POSTCON also improves endothelial function, reduces cardiomyocyte apoptosis, reduces infiltration of neutrophils and, in particular, delay the restoration of neutral $\mathrm{pH}[3,6,24-27]$. POSTCON is also a strong impulse which activates the RISK (reperfusion injury salvage kinase) pathway called the survival kinase pathway [28]. POSTCON causes an increase in the extracellular space of endogenous ligands, such as adenosine, opioids, bradykinin and PAR-2 agonists (protease activated receptor-2), which, acting on specific membrane receptors (G-protein-coupled receptors - GPCR), triggers multiple signaling pathways, in this particular pathway MAPK kinase-ERK $1 / 2$ (mitogen-activated protein kinase-MAPK, extracellular signal-regulated kinase $1 / 2$ - ERK 1/2) and PI3K/Akt (phosphoinositide 3 kinase - PI3K). This leads consequently to the closure of key mPTP channels in the mitochondrial membrane $[19,20,25]$. Recently, alternative survival pathways activated by POSTCON were discovered. The most important one is the SAFE (survivor activating factor enhancement) pathway [29]. Two years after the Zhao et al. publication, the first clinical application of modified reperfusion in patients treated with primary percutaneous coronary intervention was made [30]. Research conducted initially in small groups of patients were very promising. Several different algorithms of intermittent reperfusion 
$-3 \times 30$ s, $3 \times 60$ s, $4 \times 30$ s, $2 \times 90 s-$ were applied in different studies. It was demonstrated that this method reduces the area of myocardial infarction measured by markers of necrosis (CPK, CK-MB, cardiac troponin) and improves the function of the myocardium (SPECT, normalization of the ST segment on the electrocardiogram, myocardial blush grade (MBG), recently magnetic resonance imaging) [30-37]. In the largest trial published so far, Løngborg et al. conducted a randomized study of 118 patients with STEMI assigned to the group treated with primary $\mathrm{PCl}$ only, and subjected to further postconditioning of $4 \times 30 \mathrm{~s}$. Magnetic resonance imaging (MRI) performed after 3 months showed a significantly lower infarct zone in patients who received POSTCON (51\% vs. $63 \%, p<0.01$ ) [38]. Recent studies, however, did not confirm the cytoprotective effect of POSTCON and weakened the enthusiasm for this method $[39,40]$.

\section{Cyclosporine A}

Experimental studies in animal models have demonstrated that cyclosporine A, which is an inhibitor of MPTP channels, can effectively (by about $45 \%$ ) reduce the area of myocardial reperfusion injury. Cyclosporine inhibits the mitochondrial membrane permeability induced by preventing the calcium-dependent binding of cyclophilin D with the elements of mPTP.

The recently published randomized study of Piot et al. showed that cyclosporine A in a dose of $2.5 \mathrm{mg} / \mathrm{kg}$ of body weight, administered intravenously $10 \mathrm{~min}$ prior to percutaneous coronary angioplasty, is associated with about $40 \%$ smaller infarct area (CK-MB, MRI) than in the placebo group [41]. In the follow-up treatment with cyclosporine was associated with a reduction in infarct zone measured by MRI and lower left ventricular remodeling [42]. However, confirmation of this beneficial effect requires further studies in larger groups of patients.

\section{Adenosine}

Adenosine is one of the mediators involved in the pathophysiology of IRI. The increased leaching from the extracellular space at the time of reperfusion is one of the mechanisms encouraging the severity of necrosis in the reperfused area (purine paradox). Adenosine acts via its $A 1$ and $A 2$ receptors belonging to the family of GPCRs, which cause activation of the pathway enzymes RISK and prevent the opening of the mPTP channel. Adenosine also has a potent anti-inflammatory effect. Reduction of neutrophil infiltration and in swelling of microvascular endothelial cells contributes to reduction of the "no-reflow" phenomenon. The protective effect of adenosine, which has been observed in experimental studies, was evaluated in clinical trials. In the AMISTAD II study, patients with STEMI were treated with intravenous infusion of adenosine (70 $\mathrm{\mu g} /$ $\mathrm{kg} / \mathrm{min}$ for $3 \mathrm{~h}$ ) during the reperfusion period (thrombolysis or PCI) [43]. It was found that adenosine treatment sig- nificantly reduced infarct size, but it had no effect on the clinical outcomes with the exception of patients treated $3 \mathrm{~h}$ from the onset of symptoms [44]. In such cases a relatively large area of viable ischemic myocardium still exists and thus may be protected during reperfusion.

Marzilli et al. proposed the prophylactic administration of intracoronary adenosine during primary $\mathrm{PCl}$ [45]. They showed the effect of such administration of adenosine on myocardial reperfusion measured by MBG and normalization of the ST-segment elevations. Grygier et al. presented an improved method of infusion of adenosine [46]. They showed that intracoronary administration of the drug twice in a high dose $(2 \times 2 \mathrm{mg}$ to the left coronary artery and $2 \times 1 \mathrm{mg}$ to the right coronary artery) significantly improved perfusion measured angiographically and electrocardiographically, and also reduced the occurrence of composite clinical endpoint. However, in the recently published study SALVAGE, in which 112 patients with STEMI were evaluated, intracoronary adenosine administration at a dose of $4 \mathrm{mg}$ during primary $\mathrm{PCl}$ did not affect the size of necrosis and microvascular damage in MRI [47]. The cited studies were conducted on relatively small groups of patients; thus the clinical value and method of administration of adenosine as a routine procedure during primary $\mathrm{PCI}$ must be verified in larger clinical trials.

\section{Delta isoform of protein kinase $\mathrm{C}$ blockers}

High hopes for inhibition of reperfusion injury were associated with the molecule KAI-9803 - a peptide inhibiting the binding of the delta isoform of protein kinase $C(P K C-\delta)$ with its intracellular receptor localized in the mitochondria. Inhibition of the biological effects of $\delta$-PKC in experimental reperfusion reduced the negative impact of restoration of normal intracellular $\mathrm{pH}$, protected mitochondria, restored energy supplies and reduced cell apoptosis [48]. In animal models it reduced the infarct zone, and the overall improvement of regional myocardial contractility and coronary microvascular function was observed. The results of the clinical trial DELTA-MI which was conducted in a small group of patients seemed to be promising and confirmed the safety of use of the drug in humans [49]. However, recently presented results of the large multi-center randomized trial PROTECTION-AMI showed that 2.5-hour infusion of $\delta$-PKC inhibitor started before the opening of the infarct-related artery did not reduce enzymatic myocardial damage and did not improve the normalization of ST-segment elevations. Furthermore, there was no reduction in the necrotic area in scintigraphy after 3 months and thereas no impact on clinical outcomes [50].

\section{Other methods of prevention and treatment of ischemia-reperfusion injury}

Many other strategies and drugs potentially beneficial in prevention and treatment of IRI have also been evaluated in experimental and clinical trials. Unfortunately, near- 
ly all of them have proven to be ineffective, or difficult to use clinically during the acute phase of myocardial infarction. Treatment with antioxidants (reducing the production of free radicals) has been proved to be ineffective [51]. There were also no cardioprotective effects of magnesium treatment and glucose, insulin and potassium infusion [52]. Also ineffective and even harmful was the administration of drugs that block the $\mathrm{Na} / \mathrm{Ca}$ exchanger (cariporide, eniporide) $[53,54]$. Some positive results especially in treatment of the no-reflow phenomenon can be attributed to vasodilator drugs such as verapamil, sodium nitroprusside or nicorandil [55]. Significantly higher hopes are associated with the drugs that have been shown in experimental studies to reduce reperfusion injury through the activation of the RISK pathway. Drugs with this mechanism of action undergoing clinical evaluation include atorvastatin, erythropoietin, atrial natriuretic peptide and analogues of glucagon-like peptide-1.

Experimental studies have reported that a high dose of atorvastatin may reduce the extent of IRI. Promising results have been demonstrated by the ARMYDA-ACS study, which showed that $80 \mathrm{mg}$ of atorvastatin administered to patients with acute myocardial infarction without ST-segment elevation $12 \mathrm{~h}$ before $\mathrm{PCl}$ reduced the infarct size [56]. The Statin-AMI study examined the effectiveness of highand low-dose atorvastatin before primary PCI in STEMI. In a randomized group of 171 patients (a relatively small study group), a high dose of atorvastatin resulted in no significant clinical improvement, but it was associated with significant improvements in angiographic para-meters after treatment [57].

Erythropoietin has been assessed in the REVEAL study. Four-hour infusion of erythropoietin did not reduce the infarct size measured by MRI between the $2^{\text {nd }}$ and $6^{\text {th }}$ day of admission. In the group treated with erythropoietin adverse cardiovascular events were more frequently observed [58].

In the J-WIND study the authors tested whether the addition of atrial natriuretic peptide improves the results of reperfusion therapy [59]. The study patients were eligible for both thrombolysis and primary angioplasty. 72 -hour infusion of atrial natriuretic peptide caused a $15 \%(p=0.016)$ reduction in enzymatic infarct size and improved left ventricular ejection fraction after $6-12$ months by $2.2 \%(p=0.024)$.

In a recently published study, a group of Danish researchers evaluated exenatide (BYETTA, Amylin-Lilly USA) - an analog of glucagon-like peptide-1, which is used in the treatment of type 2 diabetes [60]. One hundred and seventy two patients with STEMI were randomized to receive an infusion of the study drug starting 15 min before $\mathrm{PCl}$ or placebo. Infusion was maintained $6 \mathrm{~h}$ after the procedure. It was confirmed that administration of the drug in the acute phase of myocardial infarction is safe and there was a significant reduction in infarct size assessed by MRI.

\section{Clinical application of cardioprotective methods during primary percutaneous coronary intervention}

May successful reperfusion therapy with primary angioplasty be supplemented by additional cardioprotective strategies to effectively protect against reperfusion injury? At present, none of them is still found to be fully recognized and the routine in clinical practice. Based on previous studies, both POSTCON and other methods used to prevent IRI can benefit patients with a high risk of STEMI, i.e. with a large area of ischemia (proximal closure of large coronary arteries) and with total ischemia time shorter than 3-4 h, or in those patients who still retain a relatively large area of viable myocardium. Final confirmation of the effectiveness of cardioprotective strategies, supporting optimal reperfusion therapy, and the widespread adoption of these methods as the standard for treatment of primary percutaneous coronary intervention therefore require further clinical trials, multi-center and in larger groups of patients, as well as the careful selection of protocols and clinical endpoints. It seems, however, that these studies are promising due to the significant potential benefits for patients with STEMI.

\section{References}

1. Kelly CE, Boura JA, Grines CL. Primary angioplasty versus intravenous thrombolytic therapy for acute myocardial infaction: a quantitative review of 23 randomised trials. Lancet 2003; 361: 13-20.

2. McManus DD, Gore J, Yarzembski J, et al. Recent trends in the incidence, treatment and outcomes of patients with STEMI and NSTEMI. Am J Med 2011; 124: 40-47.

3. Yellon DM, Hausenloy DJ. Myocardial reperfusion injury. N Engl J Med 2007; 357: 1121-1135

4. Verma S, Fedak PW, Weisel RD, et al. Fundamentals of reperfusion injury for the clinical cardiologist. Circulation 2002; 105: 2332-2336.

5. Matsamura K, Jeremy RW, Shaper J, Bechor LC. Progression of myocardial necrosis during reperfusion of ischemic myocardium. Circulation 1998; 97: 795-804.

6. Yetgin T, Manintveld OC, Duncker DJ, van der Giessen WJ. Postconditioning against ischemia reperfusion injury: ready for wide application in patients? Neth Heart J 2010; 28: 389-392.

7. Braunwald E, Kloner RA. Myocardial reperfusion: a double-edged sword? J Clin Invest 1985; 76: 1713-1719.

8. Gibbons RJ, Valeti VS, Avaoz PA, et al. The quantification of infarct size. J Am Coll Cardiol 2004; 44: 1533-1542.

9. Downey JM, Cohen MV. Why do we still not have cardioprotective drugs? Circ J 2009; 73: 1171-1177.

10. Braunwald E, Kloner RA. The stunned myocardium: prolonged, postischemic ventricular dysfunction. Circulation 1982; 66: 1146-1149.

11. Ito H. No-reflow phenomenon and prognosis in patients with acute myocardial infarction. Nat Clin Pract Cardiovasc Med 2006; 3 : 499-506.

12. Kloner RA, Ganote CE, Jennings RB. The no-reflow phenomenon after temporary coronary occlusion in the dog. J Clin Invest 1974; 54: 1496-1508.

13. Manning AS, Hearse DJ. Reperfusion-induced arrhythmias: mechanisms and prevention. J Mol Cell Cardiol 1984; 16: 497-518. 
14. Jennigs RB, Sommers HM, Smyth GA, et al. Myocardial necrosis induced by temporary occlusion of a coronary artery in dog. Arch Pathol 1960; 70: 68-78.

15. Jennings RB, Schaper J, Hill ML, et al. Effect of reperfusion late in the phase of reversible ischemic injury: changes in cell volume, electrolytes, metabolites, and ultrastructure. Circ Res 1985; 56: 262-278.

16. Braunwald E. Myocardial reperfusion, limitation of infarct size, reduction of left ventricular dysfunction and improved survival. Should the paradigm be expanded? Circulation 1989; 79: 441-444.

17. Kaname M, Richmond WJ, Jutta S, et al. Progression of myocardial necrosis during reperfusion of ischemic myocardium. Circulation 1998; 97: 795-804.

18. Jordan IE, Zhao ZQ, Vinten-Johansen J. The role of neutrophils in myocardial ischemia - reperfusion injury. Cardiovasc Res 1999; 43: 860-878.

19. Perelli MG, Pagliaro P, Penna C. Ischemia/reperfusion injury and cardioprotective mechanisms. Role of mitochondria and reactive oxygen species. World J Cardiol 2011; 3: 186-200.

20. Hausenloy DJ, Ong SB, Yellon DM. The mitochondrial permeability transition pore as a target for preconditioning and postconditioning. Basic Res Cardiol 2009; 104: 189-202.

21. Gustafsson AB, Gottlieb RA. Heart mitochondria: gates of life and death. Cardiovasc Res 2008; 77: 334-343.

22. Follette DM, Fey K, Buckberg GD, et al. Reducing postischemic damage by temporary modification of reperfusate calcium, potassium, pH, and osmolarity. J Thorac Cardiovasc Surg 1981; 82: 221-238.

23. Zhao ZQ, Corvera JS, Halkos ME, et al. Inhibition of myocardial injury by ischemic postconditioning during reperfusion: comparison with ischemic preconditioning. Am J Physiol Heart Circ Physiol 2003; 285: H579-H588.

24. Vinten-Johansen J, Granfeldt A, Mykytenko J, et al. The multidimensional physiological responses to postconditioning. Antioxid Redox Signal 2011; 14: 791-810.

25. Kin $\mathrm{H}$, Zatta AJ, Lofye MT, et al. Postconditioning reduces infarct size via adenosine receptor activation by endogenous adenosine. Cardiovasc Res 2005; 67: 124-133.

26. Ovize M, Baxter GF, Di Lisa F, et al. Postconditioning and protection from reperfusion injury: where do we stand? Position paper from the Working Group of Cellular Biology of the Heart of the European Society of Cardiology. Cardiovasc Res 2010; 87: 406-423.

27. Araszkiewicz A, Grygier M, Lesiak M, Grajek S. Postconditioning can the modified reperfusion improve the results of primary coronary angioplasty? Kardiol Pol 2012; 70: 943-947.

28. Hausenloy DJ, Lecour S, Yellon DM. Reperfusion injury salvage kinase and survivor activating factor enhancement prosurvival signaling pathways in ischemic postconditioning: two sides of the same coin. Antioxid Redox Signal 2011; 14: 893-907.

29. Lacerda L, Somers S, Opie LH, Lecour S. Ischaemic postconditioning protects against reperfusion injury via the SAFE pathway. Cardiovasc Res 2009; 84: 201-208.

30. Laskey WK. Brief repetitive balloon occlusions enhance reperfusion during percutaneous coronary intervention for acute myocardial infarction: a pilot study. Catheter Cardiovasc Interv 2005; 65: 361-367.

31. Laskey WK, Yoon S, Calzada N, Ricciardi MJ. Concordant improvements in coronary flow reserve and ST-segment resolution during percutaneous coronary intervention for acute myocardial infarction: a benefit of postconditioning. Catheter Cardiovasc Interv 2008; 72 : 212-220.

32. Thibault $\mathrm{H}$, Piot $\mathrm{C}$, Staat $\mathrm{P}$, et al. Long-term benefit of postconditioning. Circulation 2008; 117: 1037-1044.
33. Staat $P$, Rioufol $G$, Piot $C$, et al. Postconditioning the human heart. Circulation 2005; 112: 2143-2148.

34. Ma X, Zhang X, Li C, Luo MJ. Effect of postconditioning on coronary blood flow velocity and endothelial function and LV recovery after myocardial infarction. Interv Cardiol 2006; 19: 367-375.

35. Yang XC, Liu Y, Wang LF, et al. Reduction in myocardial infarct size by postconditioning in patients after percutaneous coronary intervention. J Invasive Cardiol 2007; 19: 424-430.

36. Zhao WS, Xu L, Wang LF, et al. A 60-s postconditioning protocol by percutaneous coronary intervention inhibits myocardial apoptosis in patients with acute myocardial infarction. Apoptosis 2009, 14: 1204-1211.

37. Sörensson P, Saleh N, Bouvier F, et al. Effect of postconditioning on infarct size in patients with ST elevation myocardial infarction. Heart 2010; 96: 1710-1715.

38. Lønborg J, Kelbaek H, Vejlstrup N, et al. Cardioprotective effects of ischemic postconditioning in patients treated with primary percutaneous coronary intervention, evaluated by magnetic resonance. Circ Cardiovasc Interv 2010; 3: 34-41.

39. Freixa X, Bellera N, Ortiz-Perez JT. Ischemic postconditioning revisited: lack of effects on infarct size following primary percutaneous coronary intervention. Eur Heart J 2012; 33: 103-112.

40. Heusch G. Reduction of infarct size by ischemic post-conditioning in humans: fact or fiction? Eur Heart J 2012; 33: 13-15.

41. Piot C, Croisille $P$, Staat $P$, et al. Effect of cyclosporine on reperfusion injury in acute myocardial infarction. N Engl J Med 2008; 55 : 534-543.

42. Mewton N, Crosisille P, Gahide G, et al. Effect of cyclosporine on left ventricular remodeling after reperfused myocardial infarction. J Am Coll Cardiol 2010; 55: 1200-1205.

43. Ross AM, Gibbons RJ, Stone GW, et al. A randomized, double-blinded, placebo-controlled mulitcenter trial of adenosine as an adjunct to reperfusion in the treatment of acute myocardial infarction (AMISTAD II). J Am Coll Cardiol 2005; 45: 1775-1780.

44. Kloner RA, Forman MB, Gibbons RJ, et al. Impact of time to therapy and reperfusion modality on the efficacy of adenosine in acute myocardial infarction: the AMISTAD-2 trial. Eur Heart J 2006; 27: 2400-2405.

45. Marzilli M, Orsini E, Marraccini P, Testa R. Beneficial effects of intracoronary adenosine as an adjunct to primary angioplasty in acute myocardial infarction. Circulation 2000; 101: 2154-2159.

46. Grygier M, Araszkiewicz A, Lesiak M, et al. New method of intracoronary adenosine injection to prevent microvascular reperfusion injury in patients with acute myocardial infarction undergoing percutaneous coronary intervention. Am J Cardiol 2011; 107: 1131-1133.

47. Desmet W, Bogaert J, Dubois C, et al. High-dose intracoronary adenosine for myocardial slavage in patients with acute ST-segment elevation myocardial infarction. Eur Heart J 2011; 32: 867-877.

48. Murriel CL, Churchill E, Inagaki K, et al. Protein kinase C delta activation induces apoptosis inresponse to cardiac ischemia and reperfusion damage: a mechanism involving $B A D$ and the mitochondria. J Biol Chem 2004; 279: 47985-47991.

49. Inagaki K, Chen L, Ikeno F, et al. Inhibition of delat protein kinase $C$ protects against reperfusion injury of the ischemic heart in vivo. Circulation 2003; 108: 2304-2307.

50. DELTA-MI Investigators. Intracoronary KAI-9803 as an Adjunct to primary Percutaneous Coronary Intervention for Acute ST-Segment Elevation Myocardial Infarction. Circulation 2008; 117: 886-896.

51. Flaherty JT, Pitt B, Gruber JW, et al. Recombinant human superoxide dismutase (h-SOD) fails to improve recovery of ventricular func- 
tion in patients undergoing coronary angioplasty for acute myocardial infarction. Circulation 1994; 89: 1982-1991.

52. Mehta SR, Yusuf S, Diaz R, et al. Effect of glucose-insulin-potassium infusion on mortality in patients with acute ST-segment elevation myocardial infarction: the CREATE-ECLA randomized controlled trial. JAMA 2005; 293: 437-446.

53. Theroux P, Chaitman BR, Danchin N, et al. Inhibition of sodiumhydrogen exchanger with cariporide to prevent myocardial infarction in high - risk ischemic situations: main results of GUARDIAN trial. Circulation 2000; 102: 3032-3038.

54. Zeymer U, Suryapranata H, Monassier JP, et al. The $\mathrm{Na}(+) / \mathrm{K}(+)$ exchange inhibitor eniporide as an adjunct to early reperfusion therapy for acute myocardial infarction: results of the Evaluation of the safety and Cardioprotetctive Effects of Eniporide in Acute Myocardial Infarction (ESCAMI) trial. J Am Coll Cardiol 2001; 38: 1644-1650.

55. Ono H, Osanai T, Ishizaka H, et al. Nicorandil improves cardiac function and clinical outcome in patients with acute myocardial infarction undergoing primary percutaneous coronary intervention: role of inhibitory effect on reactive specimen formation. Am Heart J 2004; 148: E15.

56. Patti G, Pacseri V, Colonna G, et al. Atorvastatin pretreatment improves outcomes in patients with acute coronary syndromes undergoing early percutaneous coronary intervention: results of the ARMYDA-ACS randomized trial. JACC 2007; 49: 1272-1278.

57. Kim JS, Kim J, Choi D, et al. Efficacy of high-dose atorvastatin loading before primary percutaneous coronary intervention in ST-segment elevation myocardial infarction. J Am Coll Cardiol Cardiovasc Interv 2010; 3: 332-339.

58. Najjar SS, Rao SV, Melloni C, et al. Intravenous erythropoietin in patients with acute ST-segment elevation myocardial infarction: REVEAL: a randomized controlled trial. JAMA 2011; 305: 1863-1872.

59. Kitakaze M, Asakura M, Kim M, et al. Human atrial natriuretic peptide and nicorandil as adjuncts to reperfusion treatment for acute myocardial infarction (J-WIND): two randomised trials. Lancet 2007; 370: 867-877.

60. Lonborg J, Vejlstrup N, Kelbaek H, et al. Exenatide reduces reperfusion injury in patients with ST-segment elevation myocardial infarction. Eur Heart J 2012; 33: 1491-1499. 